\title{
Bilingual Autobiographical Memory in Older Adult Immigrants: A Test of Cognitive Explanations of the Reminiscence Bump and the Linguistic Encoding of Memories
}

\author{
Robert W. Schrauf and David C. Rubin \\ Duke University
}

\begin{abstract}
Twelve people who emigrated as adults from Spanish-speaking cultures and then spent at least 30 years in an Anglo culture were asked to provide autobiographical memories to word cues. All communication was in Spanish on one day and English on a second. In previous studies, there has been a bump or increase in autobiographical memories for the 10 to 30 decades. Here the increase in memories followed the age of immigration and settlement, supporting a cognitive theory of the reminiscence bump. The distributions of memories across the lifespan were similar for the Spanish sessions and the English sessions. Participants identified $20 \%$ of their memories as recalled internally in the language not being used that day. For this subset of memories, events prior to migration were more frequently recalled in Spanish, whereas events after migration were more frequently recalled in English. () 1998 Academic Press
\end{abstract}

This research is motivated by two questions: (1) what, if any, is the effect of a major cultural and linguistic transition, such as immigration, on the recall of autobiographical memories? and (2) are the personal memories of persons who make such transitions preferentially sampled according to language? Based on existing theory and observation, we hypothesized that adult immigrants would show greater recall for events around the time of immigration and acculturation, that recall for events prior to immigration would emerge more readily when cued in the mother tongue, and that events after immigration would more readily surface in response to cues in the language of adoption.

\section{THE DISTRIBUTION OF PERSONAL MEMORIES ACROSS THE LIFESPAN}

The distribution of autobiographical memory (Conway \& Rubin, 1993; Rubin \& Schulkind, 1997a, 1997b) has received considerable attention in recent years. When autobiographical memories are retrieved in response to cue words and subsequently dated (Galton, 1879; Crovitz

Address correspondence and reprint requests to Robert W. Schrauf, Department of Psychology: Experimental, Box 90086, Duke University, Durham, NC 27708-0086. Fax: (919) 660-5726. E-mail: schrauf@psych.duke.edu.
\& Schiffman, 1974), the distribution of those memories across the lifespan is extremely regular across participants. Experimental research shows the following components: (a) childhood amnesia, (b) retention, and (c) reminiscence.

Childhood amnesia refers to the general inaccessibility of memories for events occurring in infancy and early childhood (Nelson, 1993; Pillemer \& White, 1989; Wetzler \& Sweeney, 1986). Retention describes enhanced memory for events which have occurred in recent years of life (Rubin, 1982; Rubin, Wetzler, \& Nebes, 1986). The reminiscence phenomenon, or "reminiscence bump," refers to the fact that participants recall a greater-number-than-expected of memories for events occurring between the ages of 10 and 30. This latter is an extremely robust effect, both in the case of normal aging (Fitzgerald \& Lawrence, 1984; Franklin \& Holding, 1977; Rubin et al., 1986; Rubin \& Schulkind, 1997a) and in cases of Alzheimer's dementia (Fromholt \& Larsen, 1991, 1992). Although the reminiscence bump is empirically robust, the explanations for it are various. These may be reduced to three classes: explanations based on (1) cognitive mechanisms, (2) formation of personal and social identity, and (3) maturational development. 
Rubin, Rahhal, and Poon (1998) employed a cognitive mechanisms approach to explain increased autobiographical memory, recall of vivid and important events, and higher preference for cultural artifacts and public events from the age period 10-30 years old. During young adulthood, a person goes through a period of marked and rapid change followed by a period of relative stability. This juxtaposition may provide the conditions for optimal remembering.

Several cognitive mechanisms account for better remembering of novel events. First, there is increased effort after meaning (Bartlett, 1916, 1932), by which a person seeks to integrate new events into existing frameworks or schemata. Second, a release from proactive interference strengthens the encoding of novel events (Underwood, 1957; Wickens, 1970; for a review, see Rubin, 1995). Third, the distinctive nature of novel events makes them more memorable (Hunt \& Einstein, 1981; Hunt \& McDaniel, 1993; Hunt \& Smith, 1996). But periods of rapid change also imply that forms of memory organization at encoding may not match those of later recall, and this makes retrieval of novel events more difficult.

Periods of stability exhibit opposite effects from periods of rapid change. Events occurring during such periods are less distinctive and are met with less effort after meaning and less release from proactive interference. These factors inhibit memory. Nonetheless, events from periods of stability may serve as patterns for future similar occurrences and benefit from spaced rehearsal (Robinson, 1992), which is an important factor in long-term memory (Bahrick, 1979; Bjork \& Bjork, 1992; Braun \& Rubin, 1998; Dempster, 1988). Periods of stability also afford stable memory organization, and this too aids in recall because cues laid down at encoding remain effective at later retrieval (i.e., encoding specificity; Tulving, 1983).

Given the increased encoding which the organism enjoys during periods of rapid change and the benefits of stable memory organization and spaced rehearsal during periods of stability, Rubin, Rahhal, and Poon (1998) reasoned that the best situation for memory is the beginning of a period of stability that lasts until retrieval. Events occurring during this time will be encoded well, retrieved regularly, and integrated into the cognitive structures being developed during the ensuing period of stability.

For example, a person might visit a foreign country for a week (period of change). Novel events during such a week might include figuring out that the postal services are administered by the banks and a first experience at dickering instead of buying at fixed prices. If the visitor never returns to the country, these events may not be memorable. However, if she stays for thirty years (period of stability) these events assume a canonical significance as "first-time events," enjoy multiple rehearsals, and benefit from newer, stable forms of memory organization corresponding to life in the new culture. Although individual lives differ and although solid data cannot be given to support this claim, adolescence and young adulthood would be the most likely time for a period of rapid change followed by the relative stability of adult life. If this were the case these cognitive mechanisms would account for the larger fund of memories sampled from ages for this period.

A second possible explanation for the greater number of retrievals from this age period is that these are the years during which a young person assumes an adult social identity. Events of this time are more memorable because they are more integral to the self narrative (Fitzgerald, 1988; Gergen \& Gergen, 1983; Robinson, 1996). To the extent that the self is an ongoing narrative or constantly updated life-story (Dennett, 1991; Linde, 1993), memories from this period are a foundation for later development, either as continuous with that foundation or as discontinuous and in need of explanation. References made back to this momentous time of life would function cognitively as rehearsals. Such spaced rehearsals make the developmental-identity formation account essentially compatible with the cognitive mechanisms account.

A third possible explanation for the greater number of recalls from ages 10 through 30 is maturational. Cognitive capacities are at their optimum during these years-probably due to faster processing. The abundant literature on 
cognitive aging suggests that the decreases in processing speed is both indicative of and perhaps causally related to various deficits (Cerella, 1985; Hale \& Myerson, 1995; Salthouse, 1996). It is possible that a person remembers more from the life period covered by the bump because the organism itself is more cognitively efficient and sensitive. Similarly, standardized tests show memory and fluid intelligence peaks in this period (Rubin et al., 1998).

In populations on which the reminiscence bump has been tested, these explanations are confounded. But by testing people who make a major change in environment, they can be separated. The first of these explanations would predict a larger number of recalls as a result of immigration; the second might; the third would not. From the perspective of the cognitive mechanisms account, the period of rapid change followed by stability in immigration is analogous to that same pattern in early adulthood. There should be a greater recall of memories corresponding to the period of change in geography, society, culture, and language followed by the longer settling process of acculturation. Moreover, because events from the first culture would no longer be as useful, they would be rehearsed less and the age 10-30 reminiscence bump would decrease. Whereas it is difficult to specify exactly at what ages the cognitive explanation mechanisms should have their major effect in most people's lives, immigration should certainly qualify as a specific time when the cognitive explanation mechanisms would be especially effective. From a developmental perspective, the permanent immigrant embarks on the project of incorporating significant sociocultural changes into his or her identity and so goes through another (though perhaps less intense) period of identity formation. Again, if this theory accounts for the reminiscence phenomenon in early adulthood, then it would suggest an analogous, but perhaps smaller, effect for the period of immigration. The maturational account, however, depends on biological age and thus would not predict a bump as a result of adult migration (because maturation would not change).

\section{BILINGUAL AUTOBIOGRAPHICAL MEMORY}

The second hypothesis concerns the effects of first and second language on the recall of autobiographical memories. Most studies of bilingual memory have concentrated on storage and processing issues concerning the bilingual's two languages, that is, how lexical and semantic components are represented in memory (for a review, see Kroll \& De Groot, 1997). Generally, this work proceeds at the level of lexical tasks, though there have been calls for concentration on "more natural, contextualized linguistic units" (Hummel, 1993). There are a handful of studies of autobiographical memory in bilinguals based on clinical data and two studies which have employed variants of the CrovitzSchiffman cuing technique.

Studies from a psychoanalytic perspective suggest that bilingual persons in therapy are better able to access childhood experience via the language spoken at the time of the experience (Aragno \& Schlachet, 1996) and also that traumatic experiences may be coded or repressed at levels differentially accessible through first and second languages (Javier, 1995). In experimental work, Javier (Javier, Barroso, \& Muñoz, 1993) had five bilingual participants relate "an interesting or dramatic life experience... in the language in which the experience took place', (p. 325) and later asked for an account of the same experience in the other language. He found richer description and more elaboration in the language of the experience. $\mathrm{He}$ argues that "language serves an encoding function which allows a person to organize better his/her experiences into categories"' (Javier \& Marcos, 1989 p. 321; Luria, 1981; Vygotsky, 1962).

Thus, the clinical data and Javier's experimental work suggest a privileged encoding of experience in the language in which the event takes place. Alternatively, the experiences may be encoded more abstractly with the sensory and descriptive terms stored separately and integrated at the time of retrieval. A rich description of culture would be stored in the syntax and semantics of its language (an issue of linguistic 
relativity, see Gumperz \& Levinson, 1996; Hill \& Mannheim, 1992). In either case, under this view, an adult who moves to a new culture, learns a new language, and spends the rest of his or her life in the culture of adoption would recall material from before the transition better in the first language rather than the second and probably vice versa.

Three studies of autobiographical memory have employed the cuing technique with bilinguals. Bugelski (1977) studied 22 adults of Spanish-speaking background (average age 55) who had not spoken Spanish for the previous 10 years. They were asked "to report on their first thoughts to 20 common words" and later "asked to locate the time period in their lives to which the "thoughts' seemed to relate" according to the following age categories: $1-15,16-$ 30,30 years and older. One month later, each participant received the same list of words in the other language. Thoughts recalled to English cue words related to later times than thoughts related to Spanish cues. Bugelski theorizes that words are like any other stimuli and enjoy a conditioned connection to imagery. The language used in childhood "retains its associated imagery" (p. 50).

This finding points in the direction of differential sampling of memory according to language. More precision is required however. $\mathrm{Bu}-$ gelski asked broadly for "first thoughts" to cue words. First thoughts could imply associations of any kind. Since we are interested in specifically autobiographical memory, the task design must include this particular request. Also, Bugelski's sample was composed of persons with "Spanish speaking backgrounds," which could include persons who were bilingual from birth and who had grown up in the United States. Limiting the sample to persons who were born and raised in a Spanish-speaking country and who later moved to the United States assures that the earliest linguistic encoding of the physical and social environment took place predominantly if not exclusively in Spanish.

Otoya (1987) studied 40 bilingual (SpanishEnglish) students aged 18-26, half of whom were monocultural ( $80 \%$ born in the USA, $20 \%$ moved to the USA before the age of 4), the other half bicultural (age of migration 7-18). Although all participants identified Spanish as their first language, the first group learned English simultaneously with Spanish and the second learned English at school age. The study included an open-ended phase in which participants were asked to think of three memories from birth to their 8th birthday and two memories from their 14th birthday until the present. This was followed by a cuing procedure. Ten words were presented in each language, six of which were translation equivalents, given first in one language and later (in the same session) in the other language. Participants recalled a specific personal memory to each word.

The analysis of memories recalled by time period showed that monocultural bilinguals consistently reported earlier memories than did bicultural bilinguals. Otoya interpreted this as the cognitive consequence of the experience of migration. By analogy with theories on childhood amnesia (Neisser, 1962; Schactel, 1947), she argued that the immigrant's assumption of new cognitive schemata, in this case culturally specific schemata, rendered premigration childhood memories less accessible because the older experiences had been processed with different cultural schemata. Interestingly, were this the case, some measure of premigration amnesia would affect all immigrants.

The analysis of the cued memories was limited to the six pairs of translation equivalents. For each pair of words, and for both monocultural and bicultural participants, the Spanish words prompted older memories than did the English translation equivalents, though analysis of only three of the six words reached statistical significance. One possible explanation for this phenomenon is that "the predominant language at the time of encoding an event becomes part of the memory trace itself'" (p. 124). An alternate explanation is that one language (Spanish) is associated with a particular time of life (childhood) and cues in that language trigger memory for the entire period. These explanations share with the previous studies the notion that the royal road to childhood memories (and, by extension, any other memories) lies through the language in which these memories took place. 
Otoya's work is directly relevant to the hypotheses of this study. The correlation of the experience of childhood migration with the age of earliest memory suggests that migration in youth aggravates childhood amnesia. Massive changes in culture and language seem to have cognitive consequences. Testing this proposition among adult immigrants, as we propose in this study, relocates the question to adult cognition. Otoya's finding that Spanish words cue older memories than do English words is enticing because it provides further justification for thinking that experiences in memory involve a specific language. Expanding the cuing procedure beyond six cue words to the one hundred of the procedure reported here allows for more detailed analysis of this phenomenon.

Finally, Marian and Neisser (1997) presented twenty Russian-English bilingual students with mean age 21.8 years, who had emigrated to the United States at the mean age of 14.2 years, with sixteen Russian-English pairs of translation equivalents in two language-specific sessions held on the same day. Participants associated autobiographical memories to the cue words and dated them afterwards. On average, memories cued in Russian were earlier than memories cued in English, and Russian cues produced more memories for events which took place in Russian while English cues produced more memories for events which took place in English. Thus, this study also finds that language at retrieval matched the language at the time of the event.

The question of whether or not autobiographical memories are language-specific has interesting consequences for the bilingual memory literature. Investigations of bilingual memory have evolved several models of bilingual lexical access to conceptual memory stores (Hamers \& Blanc, 1989; Harris, 1992; De Groot \& Kroll, 1997). An older Separate Store Model suggested that a bilingual had two lexicons which accessed two language specific memory stores (Kolers, 1978). A 'translator' made possible access to crosslinguistic stores. Though the model does not enjoy current support, the notion that autobiographical memories are somehow language-specific would be consistent with its assumptions.

In contradistinction to this model, the Common Store Model implied that a bilingual's two lexicons have access to one common conceptual store (McCormack, 1977). Successive versions of this model, called Revised Hierarchy Models (Kroll \& Stewart, 1994; Kroll \& De Groot, 1997), suggest that links between the lexicons and the common store, as well as the links between the lexicons themselves, have differential strength depending on the stages of bilingual fluency (Heredia, 1997. For both beginning and fluent bilinguals, of course, the first language lexicon would have strong direct links to the conceptual store. A beginning bilingual speaking his or her second language would have very weak links to the conceptual store and would access it primarily via translation through the first language lexicon. Very fluent bilinguals would have direct access to the conceptual store from either of their languages and would rely infrequently on translation strategies between the lexicons. Recent evidence, however, may indicate that conceptual access is implicated for all bilinguals beyond very initial stages of second language development (De Groot \& Poot, 1997).

These models would generate the following predictions regarding autobiographical memory. According to the Separate Store Model, cuing in the mother tongue should preferentially yield memories (more, or faster, or both) from Spanish contexts before migration, and cuing in the second language should preferentially yield memories (more, or faster, or both) from English contexts after migration. Presumably a Spanish cue would activate accessing from the Spanish lexicon to the Spanish memory store. In contrast, according to the Revised Hierarchy Model, language of cue should not affect the sampling of memories from certain periods of life (either as to number or retrieval time). That is: a fluent bilingual should demonstrate no differences in access to the (common store) autobiographical memory base when cued in either language. 


\section{METHOD}

\section{Participants}

Eight females and four males participants ranged in age from 61 to 69 years old $(M=$ 64.58; $S D=2.93$ ). Three were natives of Argentina, four of Cuba, one of Guatemala, two of Panama, and two of Spain. Mean years of education of participants was $15.17(S D=.80)$. All 12 of the study participants emigrated permanently to the United States between the ages of 20 and $35(M=28.00 ; S D=5.72)$ and each participant has lived in the USA for 30 years or more. Their occupations are (were) as follows: two lab technicians, three secretaries, two housewives, two accountants, one retailer, two teachers, and one travel agent. Participants were recruited through advertisements in local newspapers which asked that persons respond whose native language was Spanish and second language was English, who had lived in the United States for thirty years or more, and who were at least 60 years of age. Participants were compensated in the amount of $\$ 50$ for their participation in the two sessions of the experiment lasting approximately two hours each. The experimenter explained to all participants that the study had to do with memories for events from the personal past and that bilingualism might be a factor in memory. No further specification was made as to our suspicions about the relationship between memory and language.

Because much depends on the exact nature of the use and mastery of the participants' two languages, we describe the bilingual status of our sample in more detail than is common. Grosjean (1997, pp. 226-227) has noted the necessity of careful specification of sample characteristics when studying bilinguals in order to ensure the comparability of experimental work. In addition to demographic data, this requires specific attention to (a) the circumstances of learning the two languages, (b) the present status of the languages for the speaker (fossilization or continued growth), (c) languages known, (d) competence in understanding, speaking, reading, and writing the languages, (e) when and with whom the languages are used, (f) how much of each day is spent in bilingual or monolingual modes, and ( $\mathrm{g}$ ) amount of codeswitching usually done. For the purposes of the present study, a questionnaire based on previous work (Javier \& Marcos, 1989; Kenny, 1996; Otoya, 1987) was designed to collect and assess this information.

The sample was constructed around three critical conditions. First, it was important to assure that cognitive processing in infancy and early childhood took place exclusively, if not predominantly, in Spanish. This condition set up the contrast with the new linguistic and cultural cognitive processing which obtains with permanent migration to the USA. The second critical condition was specifically adult transition to life in the USA. The third condition was that participants learn English after childhood.

Spanish childhood. The study focuses on persons who learned their second language after childhood in order to ensure that (a) the earliest encoding of the physical, psychological, and social environment and (b) the earliest verbal contact with significant others both took place predominantly, if not exclusively, in Spanish (and not English). In this way, enculturation and socialization interface with language learning (a process termed "language socialization"; Ochs, 1988; Schieffelin \& Ochs, 1986a, 1986b) in a situation optimally monocultural and monolingual. From the linguistic perspective, early childhood may correspond to "maturationally constrained language-specific biology" (Long, 1993, p. 201; Long, 1990). Recent neuroimaging studies suggest that second language acquisition in adolescence or adulthood involves different areas of the brain than does childhood language acquisition (Kim, Relkin, Lee, \& Hirsch, 1997).

Four of our questions asked respectively: what was the first language that you understood, spoke, read, and wrote? In every case but one, the first and only linguistic experience of participants was Spanish. In the exceptional case, the participant remembered understanding and speaking both French and Spanish with her bilingual parents, but learned to read and write only Spanish. Other questions sought to establish that significant others in childhood (grandparents, parents, siblings, friends) were exclusively, or at least predominantly, Spanish speaking. Again, all participants 
TABLE 1

Experience of Learning English

\begin{tabular}{|c|c|c|c|c|}
\hline Participant & $\begin{array}{l}\text { Age at first } \\
\text { learning English }\end{array}$ & $\begin{array}{l}\text { Age at ease of } \\
\text { speaking English }\end{array}$ & $\begin{array}{l}\text { Age at } \\
\text { immigration }\end{array}$ & $\begin{array}{l}\text { Comments on first contact } \\
\text { with English }\end{array}$ \\
\hline 1 & 6 & 10 & 22 & Elementary and high school \\
\hline 2 & 7 & 9 & 26 & Grade school \\
\hline 3 & 8 & 20 & 28 & Grade school \\
\hline 4 & 12 & 16 & 21 & $\begin{array}{l}\text { Attended the English-American } \\
\text { school }\end{array}$ \\
\hline 5 & 12 & 16 & 20 & Four years of with an American tutor \\
\hline 6 & 14 & 24 & 35 & High school \\
\hline 7 & 15 & 17 & 35 & $\begin{array}{l}\text { Americans lived with my family } \\
\text { when I was fifteen }\end{array}$ \\
\hline 8 & 16 & 24 & 30 & $\begin{array}{l}\text { Two years in high school, lived in } \\
\text { England for a year at } 23\end{array}$ \\
\hline 9 & 19 & 22 & 24 & Went to London at 19 as an au pair \\
\hline 10 & 25 & 27 & 26 & At work \\
\hline 11 & 34 & 36 & 34 & Intensive course in the USA \\
\hline 12 & 35 & 37 & 35 & Working, when I came to the USA \\
\hline
\end{tabular}

Note. Comments in the last column are notes from the language background questionnaire.

remembered speaking only Spanish with childhood caregivers and playmates-with two exceptions. One person (already noted) also spoke French with her parents and siblings (though only in Spanish with her grandparents and friends). Another participant spoke Italian with his father. No participant spoke English during early childhood.

Learning English. When a second language is learned and where it is learned are important factors. Learning a second language in an environment different from the environment in which the first language was learned may involve separate encodings for separate references (Ervin \& Osgood, 1954). Bilinguals become linguistically competent in varying degrees for various domains of reference (Hamers \& Blanc, 1989 , pp. 6-14). Learning as a result of formal instruction differs from the language socialization of early childhood (Ellis \& Laporte, 1997).

Participants presented a broad picture of exposure to and learning of English. Table 1 presents this data ordered by age of first contact with English. Only two participants exhibit the "ideal" status of learning English as adults on arrival in the USA. Seven of the 12 indicate a first exposure to English in school in their countries of origin, but their use of English in these situations was largely scholastic since their daily cultural and social environments were Spanish. Nine of the 12 judged that they had achieved a "sense of some ease" in speaking English before moving to the USA.

Competence in English and patterns of use of both languages. A series of questions assessed competence in English and the patterns of use of both languages at the present time. (On the validity of such self-reports, see Fishman, Cooper, \& Ma, 1975; Lambert, Havelka, \& Crosby, 1958; MacNamara, 1967). Participants were asked to rate their abilities to understand, speak, read, and write English by supposing that their abilities in those areas in Spanish were at $100 \%$ and assigning a percentage for the corresponding ability in English. Participants' judgments of their competence were uniformly high: understanding $(M=94.75 ; S D=.90)$, speaking $(M=92.91 ; S D=8.38)$, reading $(M=96.25$; $S D=6.07)$, and writing $(M=87.91 ; S D=$ 14.99).

Developing a picture of current patterns of usage involves bringing into focus three factors: (1) linguistic demands of the social environment-an interpersonal behavioral requirement, (2) linguistic choices made by a person in the execution of private tasks - an intrapersonal be- 
TABLE 2

Exercise in Bilinguality in Social Environment: Language Currently Spoken with ...

\begin{tabular}{cllllllll}
\hline Participant & Family & In-laws & Spouse & Friends & Children & Workmates & Neighbors & Mean \\
\hline 2 & 1 & 1 & 1 & 3 & 1 & 3 & 3 & 1.86 \\
5 & 1 & 2 & 1 & 2 & 2 & 2 & 3 & 1.86 \\
7 & 1 & 1 & 1 & 2 & 2 & 3 & 3 & 1.86 \\
9 & 1 & 1 & 1 & 2 & 3 & 2 & 3 & 1.86 \\
8 & 1 & 1 & 1 & 2 & 3 & 3 & 3 & 2.00 \\
10 & 2 & 1 & 2 & 2 & 2 & 2 & 3 & 2.00 \\
11 & 1 & 1 & 2 & 2 & 2 & 3 & 3 & 2.00 \\
3 & 1 & 3 & 3 & 2 & 2 & 3 & 3 & 2.43 \\
4 & 1 & 3 & 3 & 1 & 3 & 3 & 3 & 2.43 \\
1 & 1 & 3 & 3 & 3 & 2 & 3 & 3 & 2.57 \\
6 & 1 & 3 & 3 & 2 & 3 & 3 & 3 & 2.57 \\
12 & 3 & 3 & 3 & 3 & 3 & 3 & 3 & 3.00 \\
Mean & 1.25 & 1.92 & 2.00 & 2.17 & 2.33 & 2.75 & 3.00 & 2.20 \\
\hline
\end{tabular}

Note. 1, Spanish spoken; 2, Both languages spoken; 3, English spoken.

havioral decision, and (3) degree of contact with "standardized"' sources of Spanish, which act as correctives to the erosion of the native language.

Linguistic demands of social context. Requirements made by one's social environment include language spoken with significant others (spouse, children, family, in-laws, workmates, and neighbors). More often than not, this choice is constrained by the language status of the other persons involved. Participants indicated which language they used in each type of relationship: Spanish, English, or both. Table 2 contains values for participant responses (Spanish $=1$, both languages $=2$, and English $=3$ ) and an overall average score for each participant which represents, in a crude manner, language use across social situations. Participants' involvements in interpersonal situations which require that they speak English are sufficiently extensive as to justify the assumption that a considerable portion of social cognition takes place in English. (The mean score of all 12 participants is $2.20(S D=0.38)$, which indicates that both languages are commonly employed).

Choice of internal speech. The counterpart to this social cognition is the private world of mental behaviors in which a person unconsciously and spontaneously engages a particular language. There are a variety of naturally occurring mental phenomena about which people can report interior linguistic behavior (e.g., dreams). Since it is the argument of this paper that the recall of memories is sometimes a linguistic experience, memories too would form a part of this category of intrapersonal behaviors. For this reason, we elaborated several questions of this type. If a person recalls that some private behavior (e.g., writing a note to oneself) takes place in Spanish, the behavior is assigned a 1; if in both languages, a 2; and if in English, a 3. Table 3 presents these and the results associated such internal behavior.

Participant scores show that a mix of languages is the norm; the average of all 12 participants is $2.02(S D=0.50)$. The table clearly shows that patterns of usage across a variety of mental phenomena frequently involve both languages.

Contact with standard Spanish. Participants answered a number of questions designed to assess the amount of contact they had with sources of standardized Spanish. Sustained contact with "pure sources" would have the dual effect of reinforcing Spanish as the language of experience and retarding its erosion due to misuse or lack of use (for the relationship between first language deterioration of immigrants and their degree of contact with first language and 
TABLE 3

Exercise of Bilinguality in Internal Speech

\begin{tabular}{cllllll}
\hline Participant & Feeling $^{a}$ & Self & Think & Dream & Note & Mean \\
\hline 4 & 1 & 1 & 2 & 2 & 1 & 1.40 \\
3 & 1 & 1 & 3 & & 1 & 1.50 \\
2 & 2 & 1 & 2 & 2 & 1 & 1.60 \\
7 & 1 & 2 & 2 & 2 & 1 & 1.60 \\
5 & 1 & 2 & 2 & & 2 & 1.75 \\
11 & 2 & 2 & 2 & 1 & 2 & 1.80 \\
8 & 1 & 2 & 2 & & 3 & 2.00 \\
10 & 3 & 2 & 2 & 1 & 3 & 2.20 \\
6 & 3 & 2 & 2 & 2 & & 2.25 \\
9 & 2 & 3 & 2 & 3 & 3 & 2.60 \\
12 & 1 & 3 & 3 & & 3 & 3.00 \\
1 & 3 & 3 & 3 & 1.86 & 2.09 & 2.02 \\
Mean & 1.75 & 2.00 & 2.25 & &
\end{tabular}

Note. 1, Spanish used; 2, Both languages used; 3, English used.

${ }^{a}$ The full questions were as follows: Feelings: Which language do you prefer for the expression of feelings?; Self: If you catch yourself talking to yourself, what language do you speak?; Think: If you believe that you "think' in a language, in what language do you think?; Dream: In what language do you dream?; Note: If you write a note to yourself, in what language do you write it?

culture sources, see Kenny, 1996). Ironically, the desideratum with this sample is minimal contact with standardized sources and, in fact, this describes the condition of the sample. The majority of respondents (11/12) read Spanish newspapers and/or magazines between once a month and never. While four respondents watched TV programs in Spanish several times a week, eight did so either once a month or once every several months. Participants participated in Spanish social events either every few months (8) or never (4). Visits to the country of origin were spaced between one visit a year (1 person), one visit between two and five years (6 persons), every ten years (1 person), and never (4 people). As is evident, this is not a group of people with consistent contact with standardized sources.

Sample summary. The sample is composed of 12 adult consecutive bilinguals who grew up in either Spain or Latin America and who emigrated to the United States between the ages of 20 and 35. Learning English began for 8 of the 12 in school in their home countries. No participant spoke English before the age of 6, and no participant lived in an English-speaking environment before the age of 19 (one participant lived in London for a year at age 19). All participants have lived in the United States for at least 30 years. Their associations with Spanish persons outside of their families are minimal; they live in Anglo environments and manage their affairs almost exclusively in English. Many of their private mental habits exhibit equal engagement of both languages. As their childhood experience was culturally and linguistically Spanish, so the present stage of adulthood for them is culturally and linguistically Anglo.

\section{Materials and Procedure}

All participants participated in two sessions, one in Spanish and one in English, each session lasting from an hour and a half to two hours. The order of language was counterbalanced across participants, and both sessions were conducted by the first author who is bilingual. Participants were given the option of participating in the experiment in their homes (8) or at Duke University (4).

The experimenter told the participant that he or she would be given 50 word cues and asked to associate each cue with a specific personal event from the past and to write a few words 
about the memory in the language of the day. In the interest of the preservation of privacy and the avoidance of fatigue, participants were encouraged to provide very brief descriptions and they often wrote cryptic references to their memories. One hundred cues were selected from 124 nouns used in earlier autobiographical memory studies (Rubin \& Schulkind, 1997a, 1997b). All words had been normed on a collection of rating scales (Rubin, 1980). The 24 words with the lowest imageability ratings were eliminated because in previous studies words with low imageability led to long reaction times and often no responses (Fitzgerald \& Lawrence, 1984; Rubin, 1982; Rubin \& Schulkind, 1997a). Spanish translation equivalents were made for each of the resulting 100 words and checked against a frequency list (Eaton, 1940) to ensure a common word was chosen. Lists were randomized, and half of the list was presented in one language on one day to a participant and the other half in the other language on a subsequent day to the same participant. Participants were paired so that the corresponding translations were presented to another person.

Memory recall was timed by the experimenter with a stopwatch which was activated as soon as the participant flipped a cue card until the moment the participant began writing down the description of the memory.

After completing the description of 50 memories, each person was asked to consider if he or she experienced any of the memories in the "'other' language. For example, on the day of the English session participants were told that: "Sometimes people who speak both Spanish and English say that a particular memory came to them in one of those languages. They seemed to think it in Spanish or think it in English. Now, all of the words on the cards today were in English, and you wrote down your memories in English, but I'd like you to look through your whole list and mark off any memory that you feel certain came to you in Spanish, meaning you seemed to 'think it' in Spanish, even though your description was in English.' 'Every participant understood these instructions without requiring any further clarification, that is, the task made sense to them. After completing this task in the first session, participants filled out questionnaire regarding their linguistic backgrounds.

The second session was conducted between 1 and 16 days after the first session $(M=7.41$; $S D=4.6$ ). After participants completed the tasks of the second session, they were given their memories from both days and asked to date the event represented in each of the 100 memories.

\section{RESULTS}

\section{Distribution of Memories across the Lifespan}

The ideal control group for this study would include Spanish-speaking persons of comparable cultural backgrounds who had never undergone permanent migration, that is, three native Argentines who had lived their entire lives in Argentina, four native Cubans who had lived their entire lives in Cuba, etc. Although this latter requirement complicates recruitment considerably, careful matching of cultural background would be necessary to test for cultural effects on the distribution of memories across the lifespan. Certainly, there is cultural diversity about the conditions and beliefs surrounding the life course (Becker, 1997; Spencer, 1990), and we hope that future cross-cultural fieldwork will test the influence of these on autobiographical memory.

In the meantime, reanalysis of data from previous studies of the reminiscence bump (Rubin \& Schulkind, 1997a) provides for comparisons. Participants were English speakers, aged 70 to 73, from North Carolina. These participants retrieved personal memories to the 124 cues from which the 100 cues of this study were drawn. On reanalysis, the 24 cues not used in this study were eliminated and memories for events which occurred after the age of 60 were excluded. In a decade-histogram analysis, each participant's memories were arranged in decades, 0-10, 1120 , etc., and means and standard errors were calculated.

Figure 1 displays the curve representing these English speakers' memory distributions. The reminiscence bump for ages 10 through 30 is present and decreases with the onset of the fourth decade of life. In addition, the figure 


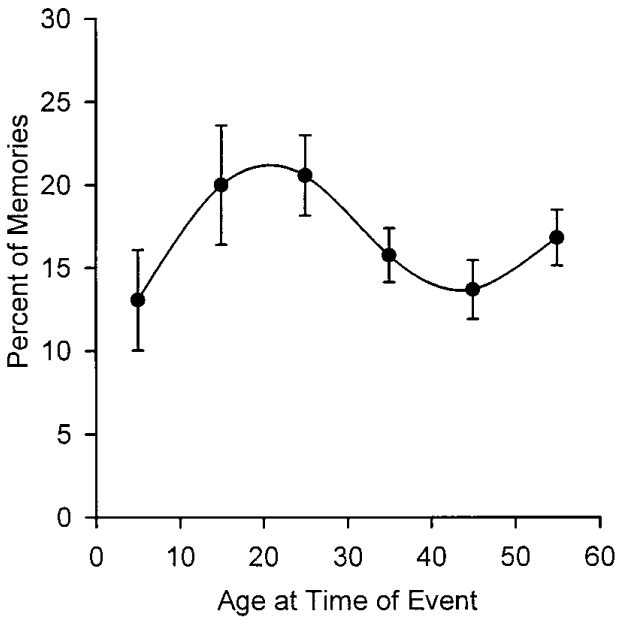

FIG. 1. Histogram of autobiographical memories of monocultural monolinguals (Rubin \& Schulkind, 1997a) reanalyzed and restricted to the 100 cues used in the present study (out of an original 124 cues). Error bars show standard errors.

displays the other two components of the autobiographical memory distribution discussed in the introduction: childhood amnesia and the recency phenomenon.

Consideration of the twelve older immigrants in terms of age-at-immigration suggests a natural break into three groups of four: ages 20-24, 26-30, and 34-35. This tripartite grouping for age-at-migration corresponds to those made in demographic studies of migration patterns. These studies corroborate at the population level the observation that people tend to migrate in early adulthood (Long, 1973; Rogers, 1979). More recently, in a closer look at migratory patters in early adulthood, Pandit (1997) notes very nearly the same groupings we found in our data: 20-24; 25-29; and 30-34.

Figure 2 shows the memory distributions of each of these three groups. Participants who emigrated earlier (20-24) reflect the usual memory distribution with an increase in number of memories in the 10-30 age range, followed by a decrease in the next two decades. In contrast, persons who emigrated later in life (ages 34-35) show a marked decrease in memories for the 10-30 range when compared with earlier immigrants and show an increase corresponding to the decade in which immigration took place. Comparing the adolescent-early adulthood bump of immigrants at ages 20-24 with the immigration bump of immigrants at ages 34-35 shows a much larger fund of memories in the bump of the first group. The 26-30 group falls in between. A 3 (age of immigration) between subject by 2 (10-30 vs 30-50) within subject ANOVA reveals two significant effects: a period main effect caused by more memories in the 10-30 period, $F(1,9)=11.41$, $M S E=123.67, p<.01$, and an age of immigration by period interaction, $F(2,9)=7.72$, $M S E=123.67, p=.01$, as just described.

These results support the first hypothesis of the study. The data suggest that immigration does in fact have an effect on the distribution of memories across the lifespan. In this study, persons who emigrated at ages $34-35$ showed depressed recall for the period of adolescence and early adulthood but increased recall corresponding to the years of immigration and settlement. In the case of the age 20-24 group, the experience of immigration occurs simultaneously with adolescence and early adulthood and may account for the comparatively higher recall seen in this group. That is, both adolescence and immigration are deemed periods of rapid change followed by stability for some domains of life.

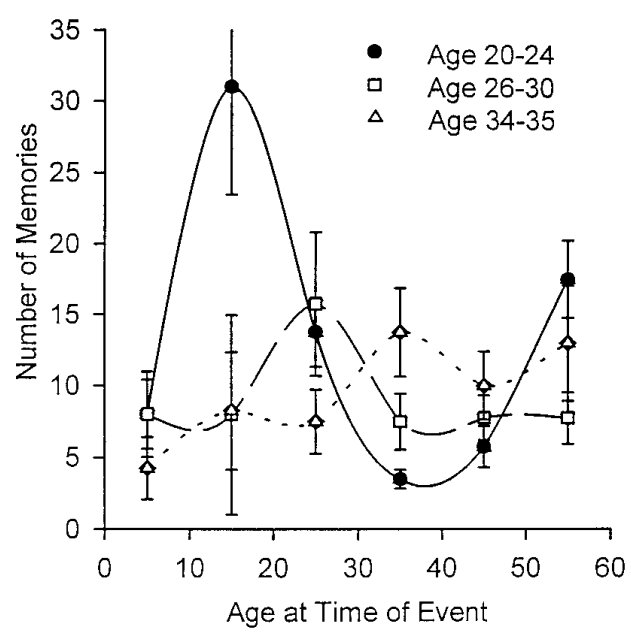

FIG. 2. Histogram of autobiographical memories of bilingual participants grouped according to age at immigration. Error bars show standard errors. 
Where these coincide, larger effects are expected.

One possible criticism of these findings is that the reported memories are selective along some dimension other than age-at-event that causes the age-at-event effect. The participants clearly each have more than 100 autobiographical memories that they could report, and, therefore, those that they do report are a highly accessible subsample (Rubin, 1982). Moreover, all memories can be seen as competing with each other because there are only 100 memories reported and reporting one memory precludes reporting another. Several lines of evidence, however, argue that the memories in the bump are not caused by just a few highly accessible memories nor are they different from nonbump memories in other easily quantifiable ways.

In other studies using word cues, the bump has appeared in roughly the same magnitude with as few as 20 memories recorded from an individual (Rubin et al., 1986) and with as many as 920 (Rubin \& Schulkind, 1997a). When important memories are requested, there can be as few as 4 or 5 (Fitzgerald, 1988; Rubin \& Schulkind, 1997b). Furthermore, in the present study there was no effect of the decade of the event on output order. If we number the first dated memory that a participant produces in each session as 1 , the second as 2 , and so forth up to a maximum possible of 50 to produce an indication of output order, then the mean output order (with standard deviation) for each of the six decades shown in Fig. 1 is 21.76 (3.97), 26.71 (8.52), 24.77 (4.46), 23.90 (6.13), 23.16 (8.06), and 24.79 (4.79). Moreover, the memories here and in other studies (Rubin \& Schulkind, 1997b) do not differ systematically across decades in reaction time.

Similarly, memories from the bump do not differ when participants rate memories on vividness, pleasantness, significance, novelty, and frequency of rehearsal (Rubin \& Schulkind, 1997b). That is memories for events dated in the 10 to 30 period are not judged as being more vivid, pleasant, significant, novel, or rehearsed than memories from other periods, though all are fairly high on these scales. Given the fact that greater recall of memories during this age period is not due to either retrieval artifacts or some difference in kind or quality of memory, age-at-event is the criterion by which differential selection occurs

\section{Memories by Language of Cue}

The second hypothesis of the study was that language of cue would differentially affect retrieval, such that Spanish cues would trigger, on average, older memories, corresponding to life in the country of origin, than memories cued in English, corresponding to life in the United States. There was evidence for this in the literature: Otoya (1987) manipulated language of cue with childhood bilinguals and found older memories to first language cues than to the English translation equivalents of the cues, and Marian and Neisser (1997) found that first language cues accessed more memories for life in the country of origin. Consequently, it was also hypothesized that memories cued in Spanish would be more numerous in the "Spanish period" and English memories more numerous in the "English period." Lastly, it was hypothesized that reaction times, the amount of time required to access and begin recording a memory, would be faster in Spanish than in English since participants would be processing in the native language. None of these hypotheses were confirmed.

For memories produced in response to Spanish cue words, the mean age of the participant at the time of the memory was 39.79 years old $(S D=19.23)$, for memories cued in English, participants' mean age was $40.55(S D=18.29)$. This difference is not significant $(t(11)=.36)$. Spanish words did not, on average, cue older memories than English words. The resulting memory distributions, are shown in Fig. 3. When the previously reported 3 (age at immigration) by 2 (period) ANOVA was expanded to a 3 by 2 by 2 (Spanish cues vs English cues) ANOVA, none of the main effects or interactions concerning language was significant.

Finally, despite the fact that Spanish was the first language of the participants-enjoying thereby a processing advantage as a result of years of familiarity, sessions in which cues and responses were in Spanish did not produce 


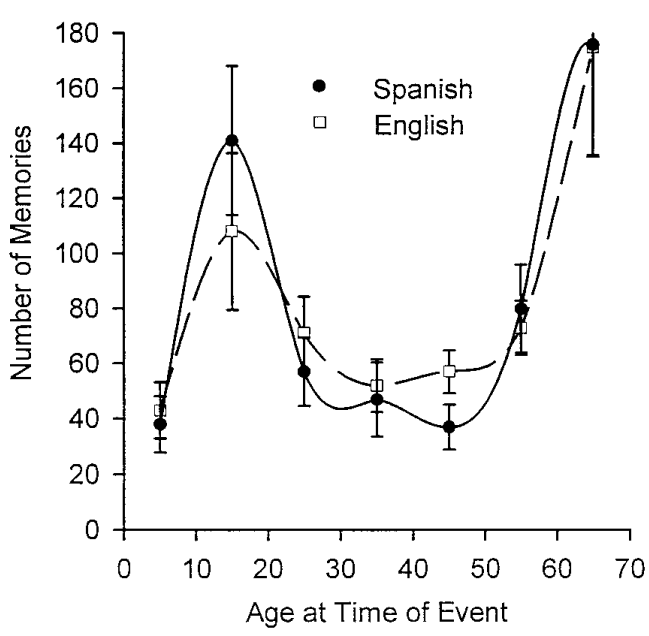

FIG. 3. Histogram of autobiographical memories of bilingual participants cued on one day by Spanish words and on another day by English words. Error bars show standard errors.

faster retrievals than did English sessions. Comparison of Spanish reaction times $(M=26.52 \mathrm{~s}$; $S D=23.71)$ and English reaction times $(M=$ $25.14 \mathrm{~s}, S D=17.63)$ showed no significant difference $(t(11)=.41)$.

Thus, the second hypothesis of the study was not confirmed. Conducting sessions in Spanish on one day-wherein cues and memory descriptions were in Spanish-and conducting similar protocols in English on another day did not produce differences by language in mean age of memories or reaction times. In sum, these procedures did not uncover "Spanish memories" as opposed to "English memories." These bilinguals had equal access to their memories in either language.

\section{Memories by Internal Language of Retrieval}

After each session, participants were asked to review their list of memories and indicate which if any seemed to them to occur in the language not used on that day. That is, participants were asked to discriminate whether the internal language of memories differed from the language of cue and written description. Of 12 participants, 10 indicated that such memories had occurred. About 20\% of the total number of memories were rated as oc- curring internally in the other language. On average, $20 \%$ of memories produced on Spanish days occurred internally in English $(M=$ 9.17, $S D=8.53)$. Approximately, $20 \%$ of memories produced on English days occurred internally in Spanish $(M=10.42, S D=$ $8.46)$. Comparison of these averages showed no significant difference $(t(11)=.47$; n.s. $)$.

For the remainder of this article, a "Spanish memory" is one identified as having occurred internally in Spanish on a day when testing was in English; an "English memory"' is one identified as having occurred internally in English on a day when testing was in Spanish. Only memories which clearly emerged in Spanish against an English background or in English against a Spanish background were identified as language specific. Our procedure allowed no way to detect memories that occurred internally in the same language that was used externally on the day of the test. Because memories that occurred in the language of the day were not counted, on logical grounds, our measure must underestimate the number of language-based memories by half.

Since participants would know on the second test day, but not the first, that questions about internal language would be asked, we tested for second-day effects and found no significant difference in numbers of memories identified as having occurred internally in the language opposite of that used externally that day (first day: $M=9.91, S D=8.64$; second day: $M=9.66$, $S D=8.42 ; t(11)=.46 ; n . s$.$) . Finally, there was$ no significant difference in reaction times for memories identified as having an internal language different from the external language of that session $(M=31.24, S D=10.86)$ and those not identified as such $(M=26.43, S D=5.30$; $t(9)=1.60)$.

By contrast with the analysis of the effect of language of cue, consideration of memories by internal language of retrieval shows significant differences in mean age of Spanish vs English memories and differences in distribution of memories (Fig. 4). Spanish memories represent events that happened earlier in life than do English memories. The average age for Spanish memories is 29.69 years $(S D=11.29)$; average for English 


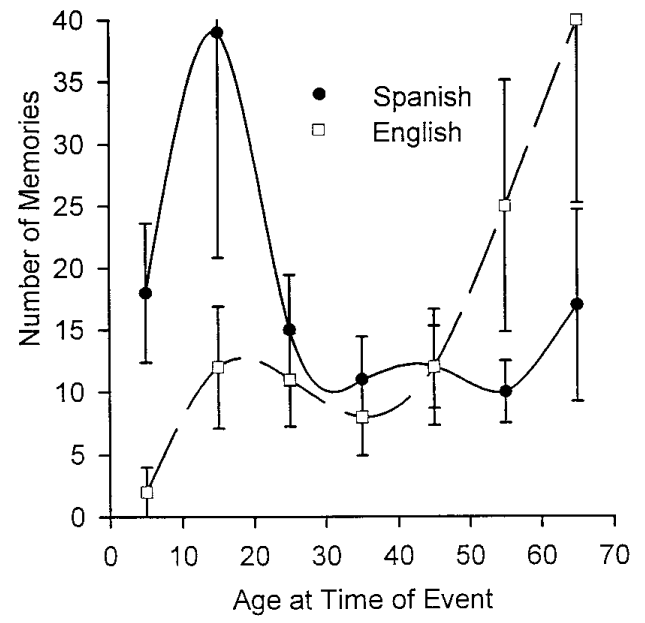

FIG. 4. Histogram of memories identified as having been recalled internally in Spanish or English. These are memories cued in one language but identified by the participant as having occurred in the other. Error bars show standard errors.

memories is 46.52 years $(S D=10.72 ; t(9)=$ $3.74 ; p<.05)$. There was no significant difference in reaction times between Spanish $(M=29.54$; $S D=12.73)$ and English memories $(M=40.91$; $S D=32.60 ; t(9)=1.07)$.

Of particular interest are the distributions of these memories. In striking contrast to the similar distributions produced by memories cued in Spanish and English, memories identified as retrieved in the other language produce quite different distributions. For the period prior to migration, the percentage of memories identified as occurring in Spanish is much higher $(82 \%)$ than of memories identified as having occurred in English (18\%). For the period after migration, the percentage of English memories is higher $(65 \%)$ than Spanish memories $(35 \%)$. With year of immigration set to zero, the distribution of memories for the two decades before and three decades after immigration that we have for all 12 participants appears as in Fig. 5. Thus, the originally hypothesized higher concentration of "Spanish" memories vs "English" memories prior to migration and vice versa after migration does obtain for memories identified as having occurred internally in a specific language.
Another phenomenon of interest is the distributions these memories form around the period of second language learning. Of 110 memories recalled in English, only two are memories of events occurring prior to the participants' first formal contact with English, and these two come from one participant.

On average, participants came to "sense of ease in speaking" English 4.19 years $(S D=$ 3.76) after initial contact with the language. When English memories are arranged around the year of "ease in speaking"' English, the vast majority of such memories appear after the year in which participants remember coming to a sense of initial competence in English. There are only 10 such memories (out of a possible 110) for events prior to that year. These latter two memory distributions, around age of first contact and age of initial competence, suggest that memories which are recalled specifically in English correspond to events which happened only after an individual had begun cognitive processing in English during exercised contact with the language.

In sum, memories identified by participants during this protocol as language specific displayed characteristics which met the expecta-

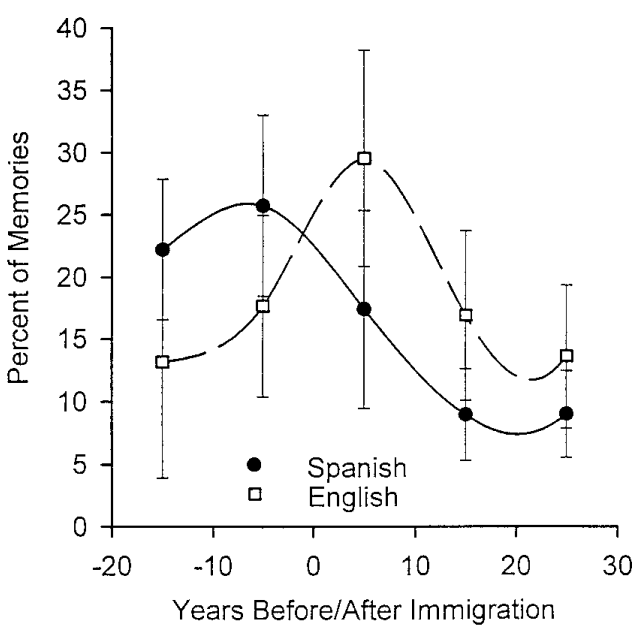

FIG. 5. Histogram of memories identified as having been recalled internally in Spanish or English ordered around year of immigration. These are memories cued in one language but identified by the participant as having occurred in the other. Year of immigration $=0$ on the $\mathrm{x}$-axis. Error bars show standard errors. 
tions which governed the study. "Spanish" memories are older than "English" memories, that is, Spanish memories correspond to events further back in life than their English counterparts. Memories occurring in Spanish are more numerous than memories occurring in English for the period prior to immigration to the United States. English memories outnumber Spanish memories for the period after immigration. Finally, memories occurring specifically in English are practically nonexistent for the events prior to a person's learning the English language and are rare for events during the period of learning English.

All of these effects occur in the absence of language of cuing effects, where effects of experimenter bias, or participant compliance with their own intuitive theories of memory, might have been expected. Our findings differ from those of previous studies, which did find language of cuing effects (Bugelski, 1977; Marian \& Neisser, 1997; Otoya, 1987) when measures of external language (of cue), and not internal language (of retrieval), are used. The fact that the older participants showed no language of cuing effects may be due to their being more accomplished bilinguals who can access knowledge of their entire lives with equal ease in both of the languages tested.

\section{DISCUSSION}

The first hypothesis predicts a reminiscence bump corresponding to the period of immigration, and the memory distribution curves are affected as predicted by the age of immigration and settlement. The second hypothesis predicts that cuing in the mother tongue vs the second language will produce older memories, but such does not occur for these bilinguals. However, when participants identify the internal language in which memories occurred, first language memories are more numerous in the first periods of life and second language memories are more numerous in the later periods of life.

\section{The Experience of Immigration and Memory}

The memory distributions of older adults in previous studies consistently exhibited three characteristics: the retention curve, childhood amnesia, and the reminiscence bump at ages 10-30. The memory distributions of these older bilingual immigrants similarly exhibit the retention curve and childhood amnesia, but, when age at immigration is examined, the reminiscence bump may be seen to shift. For persons who emigrated from their homelands in their early twenties, the usual reminiscence bump appears in the age 10-30 range. But for persons who immigrated in their midthirties, a larger percentage of memories is retrieved corresponding to the time of immigration and settlement, while the early adulthood reminiscence bump is attenuated. This result offers evidence for the adoption of the cognitive mechanisms and developmental accounts of the reminiscence bump and requires a rethinking of the maturational account.

The cognitive mechanisms account of the early adulthood reminiscence bump explains the increased number of retrievals for that period of life by theorizing that a period of rapid change (adolescence-early adulthood) followed by a period of relative stability (adulthood) provides optimal conditions for the encoding and retrieval of memories. Similarly, immigration is a time of upheaval and new experiences, that is, it is a period of rapid change, and it is followed by a period of relative stability in the subsequent routinization of life in the early years of settlement. These conditions of change followed by stability mimic those of early adulthood.

For persons who moved in their early twenties, the experience of immigration coincides with the changes of adolescence and early adulthood and their memory distributions reflect a pronounced concentration of memories for that period. Presumably immigration effects on memory are added to the adolescence-early adulthood bump and explain why this latter is so large. But for persons who moved to the USA in their midthirties, immigration represents a second period of extensive change, a period of distinctive and novel events, followed by relative stability, a period of routinization and settling. These conditions favor the encoding of memories and the tendency toward a later rem- 
iniscence bump appears in the memory distributions.

However, since immigration is itself a new period of rapid change, and since for these persons it follows so soon on the heels of adolescence and early adulthood, it should depress memory for events before immigration-which would decrease memories in the established bump. The period of rapid change represented by early adulthood is followed, not by a period of relative stability, but by a period of new rapid change. The beneficial effects of stability (spaced rehearsal and stable forms of memory organization) would not accrue for the events of late adolescence and early adulthood. The reminiscence bump corresponding to this period should be attenuated, and this is exactly what we see in the data. Thus, the cognitive mechanisms account offers an explanation for the standard reminiscence bump described in the literature, as well as for the phenomenon noted here for later immigrators: the increase in retrievals corresponding to the time of immigration and the decrease in retrievals corresponding to the standard bump.

The developmental account of the reminiscence bump suggests that events from this period are crucial in the formation of an adult social identity and form key elements of an ongoing personal narrative. By analogy, immigration is a period of assuming new competencies vis-à-vis a new sociocultural environment and its events would presumably be important elements in the life story. Adult immigration involves extensive social and cultural adjustments which would figure in the ongoing narrative account of the self. The formation of adult identity account predicts a bump where just such a bump appears. Based on this data, the developmental account cannot be empirically separated from the cognitive mechanisms account and awaits future attempts at separating these two explanations.

In contrast to the cognitive and developmental accounts for the reminiscence bump of early adulthood, the maturational account explains better memory for events of adolescence and early adulthood as the result of the heightened cognitive fitness of the organism during youth (e.g., faster processing speeds). Such an explanation predicts no change in the bump for the period of immigration since maturation. Our data cannot rule out the role of maturational factors in the presence of the adolescence-early adulthood bump, however. Processing speed and the overall fitness of the organism probably do play a role in more effective encoding of memories during this period (Rubin et al., 1998). These factors would not be as evident in middle adulthood, however, and the cognitive mechanisms account would still be needed in addition to explain the changes in the bump caused by immigration that were reported in this study.

In short, the fact that the experience of immigration displays many of the same features as the experience of coming to adulthood offers the opportunity to test the various theories posed to account for the reminiscence bump attested in the literature. The increased availability of memories corresponding to the adolescence and early adulthood and the similar increase in memories corresponding to immigration and settlement during adulthood are best explained by the memory mechanisms proper to periods of rapid change (novelty, release from proactive interference, and effort after meaning) acting in concert with mechanisms active during periods of stability (spaced rehearsal and stable memory organization).

\section{Bilingual Access to the Autobiographical Memory Base}

Our initial supposition was that manipulating the language of the session (cue and response) would produce more memories for events initially encoded in that language. Since the mean age of memories, the distribution of memories across the lifespan, and reaction times were all similar irrespective of the language of the session, we were forced to conclude that the language of the session was an ineffectual predictor of the effects of language on remembering.

One explanation is that the participants of this study were older and highly competent bilinguals who had been speaking English and living in the USA for thirty years. This may explain why our results run counter to those of Otoya 
(1987) and Marian and Neisser (1997) who used the cuing technique with participants in their twenties who had emigrated during childhood. For their participants, but not ours, external and internal language may have been confounded.

Grosjean (1995, 1997) argues that in daily life bilinguals are positioned on a situational continuum with respect to their languages. They are in monolingual mode with monolingual speakers and in bilingual mode with bilingual speakers. The languages are activated according to the situation, and activation is a question of degree, that is, the nonselected language is probably not completely deactivated even in monolingual mode. In a bilingual experiment, it is probable that the nonselected language is activated to a considerable degree. A fluent bilingual may easily employ both languages in the solitary experimental task of the study, even given the specific language of the session. By testing on separate days, we sought to minimize competition among the languages. This contrasts with the procedures of both Otoya and Marian and Neisser who tested in both languages on the same day. The surprising fact that they did find language of cuing effects in the presence of competition among the languages and we did not requires further research.

Our results point to the common sense notion that highly competent multilingual persons can access personal memories with equal facility in as many languages as they command. The performance patterns of these fluent bilinguals on the autobiographical memory task is similar to the performance patterns of fluent bilinguals on the semantic-episodic memory tasks common in laboratory studies of bilingualism and except for the findings with internal language would offer support for the Revised Hierarchy Model of Bilingual Memory.

\section{The Internal Language of Retrieval}

Participants identified certain autobiographical memories which they "thought in Spanish" despite the fact that they received cues in English and provided written descriptions of the memories in English. Conversely, certain memories were identified as having occurred in English when testing was done completely in
Spanish. Since the language of the session was manipulated, these spontaneous retrievals in the other language are unintentional mental codeswitches which seem to be caused by the contents of the memory itself. If the language of retrieval is specifically Spanish (for example), then it is possible that Spanish is specifically involved in the encoding of the memory.

These memories identified by internal language of retrieval display some interesting characteristics. First, Spanish-language memories commemorate events which cluster prior to immigration and drop off sharply in number after immigration but remain constant afterwards. English-language memories are rare for events prior to immigration but rise steadily in number afterwards and peak in the most recent past. The Spanish peak before immigration may correspond to the period of the established reminiscence bump. Since the average age at immigration is 28 , the events clustering before that year fall in the 10-30 range of the traditional bump.

Because the majority of explicitly "Spanish" retrievals commemorate events which occurred in the country of origin, in a Spanish cultural context, it is arguable that they were encoded in Spanish. Because the majority of explicitly English retrievals commemorate events which occurred in the United States, in an Anglo context, it is arguable that they were encoded in English. That the Spanish-speaking persons of this study would continue to encode memories in Spanish after immigration is not surprising since they continued using the language in varying degrees after immigration. This accounts for the constant level of Spanish retrievals after immigration. That there are instances of English retrievals before immigration is explained by the fact that the majority of participants began learning English before immigration, indeed, in the country of origin.

What is particularly striking in this regard is that, with two exceptions out of the 110 memories identified as having been recalled in English, there are no instances of such retrievals before initial formal contact with English. The first time of formal contact with English spans a large range of ages for participants in the study, 
age 6 through age 35; nevertheless, only one participant reported any memories occurring in English for before that point. Since these fluent bilinguals clearly have the capability of accessing memories from either of the languages they command, the fact that memories encoded during an exclusively Spanish period were not retrieved internally in English suggests language effects at encoding and storage.

It is possible that the internal language of retrieval phenomenon is an artifact produced by the experimental procedure. One possibility is that bilinguals dealing with a bilingual experimenter experience a high activation of both languages despite the fact that the session is conducted in one language (see Grosjean 1995, 1997). This would encourage the identification of more memories as having been recalled in the language not being used on a particular day. However, it would not account for the patterns noted above.

Another possibility is that when participants say that a memory came to them specifically in Spanish, despite responding to an English cue and writing a description in English, they are simply identifying that event as having happened in a Spanish context (e.g., with other Spanish speakers or in the country of origin). On this interpretation, they are not making a judgment based on linguistic criteria. However, the number of memories identified as having been recalled in Spanish on an English test day account for only $20 \%$ of the total memories for that day, and there are many memories for events occurring in the distant past and in a Spanish context which are not identified as 'Spanish' memories. Thus, faced with a set of memories for events which occurred in a Spanish context, participants are using some criterion to discriminate between those memories which come to them in Spanish and those which do not. Moreover, in no case did a participant express any doubt concerning the meaning of the instructions. They understand themselves to be making the discrimination based on linguistic criteria. The identification of a memory as having occurred in a particular language is not unlike the identification of certain dreams as having occurred in one or the other language-a fairly common phenomenon among bilinguals. The nature of the introspective criteria used by participants in making these judgments is intriguing and we are presently conducting research in this area.

However, if these interpretations are correct, then certain of a bilingual's retrievals are preferentially processed in one or the other language. The specific language is a phenomenal quality of the recollective experience (Tulving, 1983). Since these were memories identified as occurring in one language while the participant searched the autobiographical memory base from his or her other language, it seems logical to assume that something in the memory itself triggered the experience of cross-linguistic retrieval. Arguably, this would be the language in which the experience was encoded. To the extent that experience is mediated by language, re-experiencing an event in memory is best done in the contextual language of original encoding.

Alternatively, the semantics of the memory could be coded in language-neutral terms, for the most part, with the language component that caused the identification of an internal language of recall to be an added sensory component, much like a visual image. That is, the rhythm, body movement, sound pattern at the phonetic level or prosodic, or some other aspect of the language rather than exact wording or semantics, could be the cause of the identification.

\section{Summary}

The literature concerning the distribution of autobiographical memories across the lifespan led us to expect that persons experiencing a major transition, such as immigration to a new culture and language, would show a second reminiscence bump which would mimic the established bump of adolescence and adulthood. For persons for whom the experience of immigration takes place in adulthood, the predicted increase of memories for this period appears in the distributions. We conclude therefore that cognitive mechanisms account for the increases in retrievals in both the adolescence/early adulthood bump and the immigration bump, though maturational factors may play a role in the ear- 
lier bump as well. We also expected that cuing in the mother tongue would produce older memories with shorter reaction times than cuing in the second language, but no such difference emerged in the data. Fluent bilinguals demonstrate access to the autobiographical memory base with equal facility from either language. This supports current versions of the Revised Hierarchical Model of Bilingual Memory. Finally, we found that participants could classify retrievals as occurring in one language despite having been cued and described in the other language. Examination of this internal language of retrieval led us to conclude that the recollective experience of language-specific memories is due to the language context of encoding.

\section{REFERENCES}

Aragno, A., \& Schlachet, P. J. (1996). Accessibility of early experience through the language of origin: A theoretical integration. Psychoanalytic Psychology, 13(1), 23-34.

Bahrick, H. P. (1979). Maintenance of knowledge: Questions about memory we forgot to ask. Journal of Experimental Psychology: General, 108, 296-308.

Bartlett, F. C. (1916). An experimental study of some problems of perceiving and imaging. British Journal of Psychology, 8, 222-266.

Bartlett, F. C. (1932). Remembering: A study in experimental and social psychology. Cambridge: Cambridge Univ. Press.

Becker, G. (1997). Disrupted lives: How people create meaning in a chaotic world. Berkeley, CA: Univ. of California Press.

Bjork, R. A., \& Bjork, E. L. (1992). A new theory of disuse and an old theory of stimulus fluctuation. In A. Healy, S. Kosslyn, \& R. Shiffrin (Eds.), From learning processes to cognitive processes: Essays in honor of William K. Estes, vol. 2 (pp. 35-67). Hillsdale, NJ: Erlbaum.

Braun, K., \& Rubin, D. C. (1998). The spacing effect depends on an encoding deficit, retrieval, and time in working memory. Memory, 6, 37-65.

Bugelski, B. R. (1977). Imagery and verbal behavior. Journal of Mental Imagery, 1, 39-52.

Cerella, J. (1985). Information processing rates in the elderly. Psychological Bulletin, 98, 67-83.

Conway, M., \& Rubin, D. C. (1993). The structure of autobiographical memory. In A. F. Collins, S. E. Gathercole, M. A. Conway, \& P. E. Morris (Eds.), Theories of memory. Hillsdale, NJ: Erlbaum.

Crovitz, H. F., \& Schiffman, H. (1974). Frequency of episodic memories as a function of their age. Bulletin of the Psychonomic Society, 4, 517-551.

De Groot, A. M. B., \& Kroll, J. F. (1997). Tutorials in bilingualism: Psycholinguistic perspectives. Mahwah, NJ: Erlbaum.

De Groot, A. M. B., \& Poot, R. (1997). Word translation at three levels of proficiency in a second language: The ubiquitous involvement of conceptual memory. Language Learning, 47(2), 215-264.

Dempster, F. N. (1988). The spacing effect: A case study in the failure to apply the results of the psychological research. American Psychologist, 43, 627-634.

Dennett, Daniel C. (1991). Consciousness explained. Boston: Little, Brown, and Company.

Eaton, H. S. (1940). Semantic frequency lists: For English, French, German, and Spanish: A correlation of the first six thousand words in four single language frequency lists. Chicago: Chicago Univ. Press.

Ellis, N. C., \& Laporte, N. (1997). Contexts of acquisition: Effects of formal instruction and naturalistic exposure on second language acquisition. In A. M. B. De Groot \& J. F. Kroll (Eds.), Tutorials in bilingualism: Psycholinguistic perspectives (pp. 53-83). Mahwah, NJ: Erlbaum.

Ervin, S. M., \& Osgood, C. E. (1954). Second language learning and bilingualism. Journal of Abnormal and Social Psychology, Supplement, 49, 139-146.

Fishman, J. A., Cooper, R. A., \& Ma, R. (1975). Alternative measures of bilingualism. In J. A. Fishman, R. A. Cooper, \& R. Ma (Eds.), Bilingualism in the barrio (pp. 483-512). Bloomington, IN: Indiana Univ. Press.

Fitzgerald, J. M. (1988). Vivid memories and the reminiscence phenomenon: The role of a self-narrative. $\mathrm{Hu}$ man Development, 31, 261-273.

Fitzgerald, J. M., \& Lawrence, R. (1984). Autobiographical memory across the lifespan. Journal of Gerontology, 36.

Franklin, H. C., \& Holding, D. H. (1977). Personal memories at different ages. Quarterly Journal of Experimental Psychology, 29, 527-532.

Fromholt, P., \& Larsen, S. F. (1991). Autobiographical memory in normal aging and primary degenerative dementia (dementia of the Alzheimer's type). Journal of Gerontology: Psychological Sciences, 46, 85-91.

Fromholt, P., \& Larsen, S. F. (1992). Autobiographical memory and life history narratives in aging and dementia (Alzheimer type). In M. A. Conway, D. C. Rubin, H. Spinnler, \& W. A. Wagenaar (Eds.), Theoretical perspectives on autobiographical memory (pp. 413-426). Dordrecht, The Netherlands: Kluwer Publishing.

Galton, F. (1879). Psychometric experiments. Brain, 2, 149-162.

Gergen, K. J., \& Gergen, M. M. (1983). Narratives of the self. In T. R. Sarbin \& K. E. Scheibe (Eds.), Studies in social identity (pp. 254-273). New York: Praeger.

Grosjean, F. (1995). A psycholinguistic approach to codeswitching: The recognition of guest words by bilinguals. In L. Milroy \& P. Muysken (Eds.), One speaker, two languages: Cross-disciplinary perspectives on 
code-switching (pp. 259-275). New York: Cambridge Univ. Press.

Grosjean, F. (1997). Processing mixed language: Issues, findings, and models. In A. M. B. De Groot \& J. F. Kroll (Eds.), Tutorials in bilingualism: Psycholinguistic perspectives (pp. 225-254). Mahwah, NJ: Erlbaum.

Gumperz, J. J., \& Levinson, S. C. (1996). Rethinking linquistic relativity. New York: Cambridge University Press.

Hale, S., \& Myerson, J. (1995). Fifty years older, fifty percent slower? Meta-analytic regression models and semantic context effects. Aging and Cognition, 2, 132145 .

Hamers, J. F., \& Blanc, M. H. A. (1989). Bilinguality and bilingualism (Rev. ed.). New York: Cambridge Univ. Press.

Harris, R. J. (Ed.). (1992). Cognitive processing in bilinguals. Amsterdam: Elsevier.

Heredia, Roberto R. (1997) Bilingual memory and hierarchical models: A case for language dominance. Current Directions in Psychological Science, 6, 34-39.

Hill, J. H., \& Mannheim, B. (1992). Language and world view. Annual Review of Anthropology, 21, 381-406.

Hummel, K. M. (1993). Bilingual memory research: From storage to processing issues. Applied Psycholinguistics, 14, 267-284.

Hunt, R. R., \& Einstein, G. O. (1981). Relational and item-specific information in memory. Journal of Verbal Learning and Verbal Behavior, 20, 497-514.

Hunt, R. R., \& McDaniel, M. A. (1993). The enigma of organization and distinctiveness. Journal of Memory and Language, 32, 421-445.

Hunt, R. R., \& Smith, R. E. (1996). Accessing the particular from the general: The power of distinctiveness in the context of organization. Memory and Cognition, 24, 217-225.

Javier, R. A. (1995). Vicissitudes of autobiographical memories in a bilingual analysis. Psychoanalytic Psychology, 12(3), 429-438.

Javier, R. A., Barroso, F., \& Munoz, M. A. (1993). Autobiographical memory in bilinguals. Journal of Psycholinguistic Research, 22, 319-338.

Javier, R. A., \& Marcos, L. R. (1989). The role of stress on the language-independence and code-switching phenomenon. Journal of Psycholinguistic Research, 18, $449-472$.

Kenny, K. D. (1996). Language loss and the crisis of cognition: Between socio- and psycholinguistics. New York: Mouton de Gruyter.

Kim, K. H. S., Relkin, N. R., Lee, K.-M., \& Hirsch, J. (1997). Distinct cortical areas associated with native and second languages. Nature, 388(July 10, 1997), 171-174.

Kolers, P. A. (1978). On the representation of experience. In D. Gerver \& H. W. Sinaiko (Eds.), Language, interpretation, and communication. New York: Plenum Press.

Kroll, J. F., \& De Groot, A. M. B. (1997). Lexical and conceptual memory in the bilingual: Mapping form to memory in two languages. In A. M. B. De Groot \& J. F. Kroll (Eds.), Tutorials in bilingualism: Psycholinguistic perspectives (pp. 169-199). Mahwah, NJ: Erlbaum.

Kroll, J. F., \& Stewart, E. (1994). Category interference in translation and picture naming: Evidence for asymmetric connection between bilingual memory representations. Journal of Memory and Language, 33(2), 149174.

Lambert, W., Havelka, J., \& Crosby, C. (1958). The influence of language acquisition contexts on bilingualism. Journal of Abnormal and Social Psychology, 56, 239244.

Linde, C. (1993). Life stories: The creation of coherence. Oxford: Oxford Univ. Press.

Long, L. (1973). New estimates of migration expectancy in the United States. Journal of the American Statistical Association, 68, 37-43.

Long, M. H. (1990). Maturational constraints on language development. Studies in Second Language Acquisition, 12(3), 251-85.

Long, M. H. (1993). Second language acquisition as a function of age: Research findings and methodological issues. In K. Hyltenstam \& A. Viberg (Eds.), Progression and regression in language: Sociocultural, neurophysiological, and linguistic perspectives (pp. 178195). New York: Cambridge Univ. Press.

Luria, A. (1981). Language and cognition. Washington, D.C.: Winston.

MacNamara, J. (1967). How can one measure the extent of a person's bilingual proficiency? Paper presented at the Description and Measurement of Bilingualism: An International Seminar (University of Mocton), Toronto, Ontario, Canada.

Marian, V., \& Neisser, U. (1997) Autobiographical memory in bilinguals. Poster session presented at the 38th Annual Meeting of the Psychonomic Society, Philadelphia, PA.

McCormack, P. D. (1977). Bilingual linguistic memory: The independence-interdependence issue revisited. In P. A. Hornby (Ed.), Bilingualism: Psychological, social, and educational implications. New York: Academic Press.

Neisser, U. (1962). Culture and cognitive discontinuity. In T. E. Gladwin \& W. Sturtevant (Eds.), Anthropology and human behavior (pp. 54-71). Washington, D.C.: Anthropology Society of Washington.

Nelson, K. (1993). Explaining the emergence of autobiographical memory in early childhood. In A. F. Collins, S. E. Gathercole, M. A. Conway, \& P. E. Morris (Eds.), Theories of memory (pp. 355-385). Hillsdale, NJ: Erlbaum.

Ochs, E. (1988). Culture and language development: Language acquisition and language socialization in a $\mathrm{Sa}$ moan village. Cambridge: Cambridge Univ. Press.

Otoya, M.-T. (1987). A study of personal memories of bilinguals: The role of culture and language in mem- 
ory encoding and recall. Unpublished doctoral dissertation, Harvard University, Cambridge, MA.

Pandit, Kavita. (1997). Demographic cycle effects on migration timing and the delayed mobility phenomenon. Geographical Analysis, 29(3), 187-199.

Pillemer, D. B., \& White, S. H. (1989). Childhood events recalled by children and adults, Advances in Child Development 21, pp. 297-340.

Robinson, J. A. (1992). First experience memories: Contexts and functions in personal histories. In M. A. Conway, D. C. Rubin, H. Spinnler, \& W. Wagenaar (Eds.), Theoretical perspectives on autobiographical memory (pp. 223-239). Dordrecht, The Netherlands: Kluwer Academic.

Robinson, J. A. (1996). Perspective, meaning, and remembering. In D. C. Rubin (Ed.), Remembering our past: Studies in autobiographical remembering (pp. 199217). Cambridge: Cambridge Univ. Press.

Rogers, A. (1979). Migration patterns and population redistribution. Regional Science and Urban Economics, 9, 275-310.

Rubin, D. C. (1980). 51 Properties of 125 words: A unit analysis of behavior. Journal of Verbal Learning and Behavior, 19, 736-755.

Rubin, D. C. (1982). On the retention function for autobiographical memory. Journal of Verbal Learning and Verbal Behavior, 21, 21-38.

Rubin, D. C. (1995). Memory in oral traditions: The cognitive psychology of epic, ballads, and counting out rhymes. New York: Oxford Univ. Press.

Rubin, D. C., Rahhal, T. A., \& Poon, L. W. (1998). Things learned in early adulthood are remembered best. Memory and Cognition, 26(1), 3-19.

Rubin, D. C., \& Schulkind, M. D. (1997a). The distribution of autobiographical memories across the lifespan. Memory and Cognition.

Rubin, D. C., \& Schulkind, M. D. (1997b). The distribution of important and word cued autobiographical memo- ries in 20-, 35-, and 70-year-old adults. Psychology and Aging.

Rubin, D. C., Wetzler, S. E., \& Nebes, R. D. (1986) Autobiographical memories across the lifespan. In D. C. Rubin (Ed.), Autobiographical memory (pp. 202-221). New York: Cambridge Univ. Press.

Salthouse, T. A. (1996). The processing-speed theory of adult age differences in cognition. Psychological Review, 103, 403-428.

Schactel, E. G. (1947). On memory and childhood amnesia. Psychiatry, 10, 1-26.

Schieffelin, B. B., \& Ochs, E. (1986a). Language socialization. In B. Siegel (Ed.), Annual Review of Anthropology (pp. 163-191). Palo Alto, CA: Annual Reviews.

Schieffelin, B. B., \& Ochs, E. (Eds.). (1986b). Language socialization across cultures. Cambridge: Cambridge Univ. Press.

Spencer, P. (1990). The riddled course: Theories of age and its transformations. In P. Spencer (Ed.), Anthropology and the riddle of the sphinx (Vol. 28, ). New York: Routledge.

Tulving, E. (1983). Elements of episodic memory. Oxford, UK: Clarendon Press.

Underwood, B. J. (1957). Interference and forgetting. Psychological Review, 64, 49-59.

Vygotsky, L. S. (1962). Thought and language. Cambridge, MA: MIT Press.

Wetzler, S. E., \& Sweeney, J. A. (1986). Childhood amnesia: An empirical demonstration. In D. C. Rubin (Ed.), Autobiographical memory (pp. 191-200). Cambridge: Cambridge Univ. Press.

Wickens, D. D. (1970). Encoding categories of words: An empirical approach to meaning. Psychological Review, 77, 1-15.

(Received January 14, 1998)

(Revision received April 23, 1998) 